\title{
Petit Mal Seizure
}

National Cancer Institute

\section{Source}

National Cancer Institute. Petit Mal Seizure. NCI Thesaurus. Code C50436.

Generalized seizure that manifests in a form of a brief episode of impairment of consciousness with or without accompanying motor phenomena such as clonic-tonic components, automatisms, or autonomic components. 